
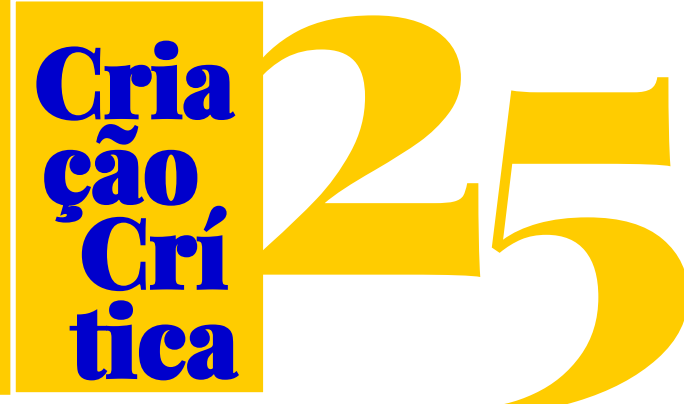

\title{
ENTRE NOMES PARTIDOS E CORPOS PRO(S)TÉTICOS, AS REGRAS DE UM JOGO DUPLO
}

Gabriela Semensato Ferreira ${ }^{1}$

\begin{abstract}
RESUMO: Em Double Game (2007 [1998]), Sophie Calle elabora um projeto colaborativo com Paul Auster a partir de um trecho de Leviathan (1992), do escritor norte-americano. No romance de Auster, a personagem Maria Turner, inspirada na vida e na obra dessa artista francesa, é apresentada. Ao analisar as regras desse jogo, Calle, por sua vez, insere o trecho sobre Maria em seu livro. Porém, realiza no texto operações de corte e enxerto, marcadas pela cor vermelha. Neste artigo, propomos pensar o excerto em questão como suplemento, avaliando como este transborda os limites da narrativa de Auster, e como articulam-se, nesse gesto ou jogo, linguagens e discursos diversos. Para isso, realizam-se recortes necessários, considerando, como parte do corpo ou corpus textual, trabalhos teórico-poéticos como Prosthesis (1995), de David Wills, e Gramatologia (1973), de Jacques Derrida. Assim, sugerimos uma aproximação entre as ideias de prótese e suplemento, para propor formas de ver e de ler essas obras de arte a partir das duplicações e duplicidades que encenam. Trata-se, portanto, não apenas da noção de duplo, mas da ficção das escrituras de si desses artistas, e da tensão que se dá pela vinculação e divisão de nomes próprios em suas obras. PALAVRAS-CHAVE: jogo duplo; suplemento; prótese; corpo; nome próprio
\end{abstract}

\section{BETWEEN DIVIDED NAMES AND PROSTHETIC BODIES, THE RULES OF A DOUBLE GAME}

\begin{abstract}
In Double Game (2007), Sophie Calle develops a collaborative project with Paul Auster by taking as a starting point an excerpt from Leviathan (1992), by the North-American writer. In this novel, the character Maria Turner is presented, inspired by the life and works of the French artist. After analyzing what she calls "the rules of the game" of Auster's work, Calle inserts the excerpt about Maria in her own book. However, she cuts and grafts this text, using the color red. In this article, we consider the mentioned passage a supplement and evaluate how it transposes the limits of Auster's narrative, as well how different languages and discourses are articulated in this gesture or game. For this purpose, some sectioning of the textual corpus, or of the body of texts, is necessary. Thus, the choice of David Wills' Prosthesis (1995) and Jacques Derrida's Grammatology (1973), in special, as theoretical-poetic references for this article, which also motivates the approximation of ideas such as "prosthesis" and "supplement", so as to offer ways of regarding and reading these works of art in light of the duplications and duplicities they perform. Consequently, not only the notion of the double is taken into account, but also the fictional dimension of these artists' "writing of the self", and the tension that arises from the linking and division of the proper names in these works.

KEYWORDS: double game; supplement; prosthesis; body; proper name
\end{abstract}

\footnotetext{
${ }^{1}$ Doutora em Letras - Estudos literários pela Universidade Federal do Rio Grande do Sul e atualmente professora substituta de Letras na Universidade Federal de Pelotas. Contato: gabisemensato@gmail.com.
} 
Ao longo de séculos da história da arte, diferentes contatos entre a literatura e as artes visuais têm sido estabelecidos. Talvez um dos grandes potenciais a unir essas linguagens seja também a razão para representarem tamanho risco a Estados autoritários: sua capacidade de falar do ser humano e de sua própria linguagem e identidade, ou seja, falar de si, colocar-se como corpo em imagem, pensar sobre o que nos torna o que somos e o que nos aflige enquanto seres pensantes e desejantes. A tradição, durante a Idade Média, via a pintura, por exemplo, como uma forma de ter acesso, ainda que fugaz, à alma - através do olho, o órgão de percepção de sentidos mais espiritual e como um espelho, onde se podiam ver reflexos do mundo (WEISSTEIN, 1982). Ainda assim, essa mesma tradição desconfiava desse poder, adotando por isso uma atitude teológica conflituosa em relação ao órgão da visão, em especial, de acordo com Ulrich Weisstein (1982). Já a literatura, pelo menos desde Platão, pode ser vista como transgressiva. O filósofo sustentava que o poeta deveria ser expulso da República, ainda que envolto em grandes homenagens. Isso porque a poesia - em especial a poesia imitativa, ou seja, a que consegue refletir o que ocorre na natureza - coloca em questão a representação do ser e, por isso mesmo, as próprias bases do que se pode considerar ser.

O que dizer, então, sobre a visualidade na/da literatura, ou da dimensão poética das artes visuais, de sua constituição também como texto? Isto é, o que dizer, não apenas do contato entre essas artes, mas dos pontos em que convergem, ou se misturam, das obras que são consideradas híbridas, ou então que revelam certa inespecificidade (GARRAMUNO, 2014), em termos de categorias? Em Literature and the Visual Arts, Ulrich Weisstein explica que houve, durante alguns séculos, um esforço de separação entre essas manifestações artísticas. Nas eras clássica e neoclássica, por exemplo, defendia-se a pureza dos tipos, e a tendência era olhar interrogativamente para formas mistas e simbióticas. Os Românticos, porém, foram contra a hierarquia clássica, que colocou a pintura em destaque no Renascimento, e caminharam em direção à simbiose, realizada através da sinestesia, que significava a fusão dos sentidos. A obra de Marcel Proust, posterior a essa fase, é marcante, nesse sentido, já que Em busca do tempo perdido (1913) revela o olfato e o paladar como catalisadores da memória.

Entre os gêneros literários que então surgem conectados às artes plásticas estão o poema icônico e um tipo de poesia que parece ter originalmente servido propósitos ritualísticos, uma "inscrição dedicatória em um objeto religioso ou de culto cujo formato exterior ele reproduzia verbal e visualmente" (WEISSTEIN, 1982, p. 253). Essa poesia teria antecipado trabalhos modernos, como os caligramas de Guillaume Apollinaire. Na virada do século XX, a iluminação recíproca (KORFMANN, 2011) entre literatura e artes visuais torna-se o centro de estudos comparativos, em que se percebem as técnicas tomadas de empréstimo entre uma e outra. Entretanto, por vezes essa proximidade ainda é baseada principalmente em sua natureza mimética.

Como se percebe, os modos de comparar estas artes permanece uma questão disputada. Weisstein, assim como Alain Badiou (2002), recusa-se a considerá-las através de um ponto de vista apenas estético, já que a Estética, como ramo da filosofia, opera de acordo com categorias estabelecidas a priori. Seria preferível, assim, partir da própria linguagem observada nessas artes para

\footnotetext{
${ }^{2}$ Este trabalho parte de pesquisa relacionada à tese de Doutorado deste autora, publicada em 2019.
} 


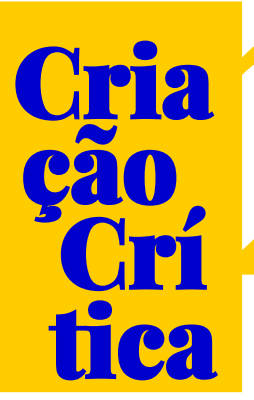

então desenvolver uma investigação acerca de suas proximidades e também das tensões e ambiguidades que se criam em obras ditas híbridas. Com isso, um dos principais objetivos deste trabalho, ao verificar essas relações, é considerar o pensar poético dos textos verbovisuais analisados, assim como as operações realizadas nas obras estudadas que possibilitem identificar seus cruzamentos.

Assim, partimos do romance Leviathan (1992), do escritor norte-americano Paul Auster, e do livro intitulado Doubles-Jeux, ou Double Game $(1999 / 2007)^{3}$, da artista francesa Sophie Calle. As operações mais relevantes que se pode destacar, em uma leitura comparativa, são: o corte, o enxerto (ou implante) e a articulação. Nomeamos articulação, aqui, a forma como esses trabalhos juntam ou conectam (sem unir totalmente) diferentes discursos e linguagens. Para isso, foi preciso dissecar esses corpos, observando suas formas. Dessas observações, surgem corpos híbridos, prostéticos, que serão descritos, e surge também a necessidade de os nomear, o que envolve espécies de jogos de palavras, levando em conta os nomes dos artistas-criadores.

Além das articulações entre linguagens artísticas e discursos (ficcionais, teóricos e críticos, por exemplo), percebe-se neste caso também a articulação conceitual descrita por Derrida em Disseminação (1981). Ela não permite chegar a uma solução especulativa entre dois opostos, como alma e corpo, porque refere o nome de um desses termos ao fora da oposição. Assim, instaura-se uma espécie de crise do versus, em que se rejeitam esses tipos de binarismos.

É preciso ainda deixar claro que o escrever anatômico de que falamos (e o qual realizamos) em certa medida aproxima-se do que constrói Jean-Luc Nancy em Corpus (2000). Ao discutir sobre o que, de uma escrita, não é para ler, em outras palavras, o corpo - como letra mais recuada e desconstruída que toda literalidade, como linguagem enquanto corpo - Nancy aborda a escrita do signo anatômico de si, que não significa, mas corta, aparta e expõe, deixando correr o animal do discurso, sua repetição, seus acasos, improvisações e desvios. Desliza, assim, para a anatomia de um corpus, distanciando-se, entretanto, da anatomia filosófico-médica da dissecação, do desmembramento dialético dos órgãos e das funções. Por outro lado, vai em direção à anatomia da enumeração, das configurações, da plasticidade, das maneiras de ser, de estados-de-corpo, etc.

Portanto, não refutamos, propriamente, a dissecação, mas sim seu fazer dialético (órgãos e suas funções, cada qual com uma), preferindo, como o teórico, adotar o trabalho da enumeração, dos andares e procedimentos. Por isso, partimos primeiramente do corpo de Leviatã e dele extraímos, em seguida, o corpo transmudado de Maria, personagem que age como substituta (ou stand-in) de Sophie Calle, nesse romance. Percebe-se, com isso, que, enquanto corpo monstruoso, Leviatã, de Auster, é enxertado com elementos diferentes, cruzado incessantemente por outros corpora, como os cruzamentos em um tecido, no tear de Ariadne, ou na teia da aranha. Mas também sofre cortes quando é parcialmente inserido em Jogo duplo, por Sophie Calle, a qual comenta a narrativa e também parte dela para desenvolver outro trabalho. Isso se dá, portanto, através de operações no corpo, praticadas por instrumentos específicos, técnicas artísticas. Esses procedimentos levam à percepção, na malha textual, desses corpos estranhos, entre eles Maria. Por isso, recortarei o Jogo duplo, publicado pela primeira vez em 1998, mas em sua tradução, transformado, aqui, na edição em língua inglesa de 2007.

Iniciamos pela compreensão de que um corpo - como aqueles de que aqui tratamos - não é um todo uno, um indivíduo separado de um contexto, nem passível de ser totalmente decifrado, desvendando, como explica Judith Butler, em Relatar a si mesmo (2015). Revela-se, nesses textos, uma

\footnotetext{
${ }^{3}$ Para este trabalho, foram utilizadas as versões de ambas as obras na língua inglesa: Leviathan (1992) e Double Game (2007). Para facilitar a compreensão, no entanto, utilizaremos aqui as versões em língua portuguesa desses títulos.
} 


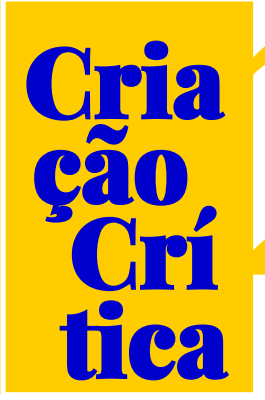

certa opacidade, a qual se deve também às articulações criadas entre sua forma e seu próprio pensamento. Isso porque conectam, em um mesmo espaço, elementos diferentes que formam um corpo misto, híbrido e que, ao mesmo tempo, se pensa constantemente, pensa sobre seu próprio fazer, e também sobre aquele que o faz, o criador, o artista. Envolvem, por isso, autorreflexividade.

\section{Nomes partidos}

Em 1992, Paul Auster publica Leviatã. No romance, descrevem-se detalhes sobre a vida de Maria Turner, uma personagem que se destaca, apesar da brevidade de sua participação nessa história. Maria é uma artista cujo trabalho é "muito pessoal para ser pensado dentro de um meio particular ou disciplina" (AUSTER, 1992, p. 60 apud CALLE, 20074). Isso porque, para ela, viver sempre veio primeiro - "living always came first" (ibidem). Esse comentário sobre o trabalho de Maria é feito por Peter, o narrador-protagonista de Leviatã, e pode ser lido de pelo menos duas formas. Primeiramente e de forma mais evidente, como a crítica de um leitor que, na ficção e fora dela ${ }^{5}$, também conhece a artista pessoalmente. Afinal, além de serem amigos, nesse momento eles têm um caso. Em segundo lugar, essa crítica pode ser direcionada não apenas aos trabalhos de Maria, mas também a Leviatã, narrativa de Auster. Nesse sentido, trata-se de uma metaficção, que envolve autorreferencialidade e autorreflexão, isto é, um pensamento relativo ao próprio texto que o enuncia.

No início desse romance, descobre-se que um homem chamado Benjamin Sachs morreu enquanto tentava construir uma bomba. Peter tomou para si o projeto de Sachs, seu segundo livro, que também se intitularia Leviatã. Como escritor, Sachs gostava de contar histórias sobre coincidências envolvendo figuras históricas. O romance que passa a ser de Peter é caracterizado como uma "performance-turbilhão" ("whirlwind performance"), já que pula de um narrador em terceira pessoa para um em primeira pessoa, em entradas de diários e cartas (AUSTER, 1992, p. 42). Mais uma vez, essa descrição se encaixa quase perfeitamente ao que acontece com textos publicados por Auster, como Leviatã ou A Invenção da Solidão (2010). As histórias reais que mais parecem ficção são também retomadas em diversos momentos.

Coincidentemente ou não, a expressão histórias reais, empregada algumas vezes por Auster, é também o título de uma obra de Sophie Calle publicada no Brasil, em 2009. É nesse contexto, e a partir desse ponto de contato, que se situa o trecho acerca de Maria, em Leviatã. Adotando o projeto de performance descrito no próprio romance - um turbilhão que lembra o movimento em espiral Auster constrói essa personagem baseada na artista francesa Sophie Calle. Parte dos trabalhos atribuídos a Maria, no romance, podem ser associados a projetos de Calle. Partes são completas invenções do autor.

Próximo aos dados catalográficos do livro de Auster, encontra-se a primeira pista para a aproximação de Maria e Calle: a menção de seu nome, ainda que não atrelado ao da personagem. "O

\footnotetext{
${ }^{4}$ Todas as referências a Leviatã nesta seção provêm do excerto desse livro (p. 60 a 67) encontrado no início de Jogo duplo, de Sophie Calle. Essas citações foram traduzidas por mim. Porém, para as outras referências a Leviatã, sobre seu enredo ou estrutura, por exemplo, utilizei a edição de 1993, já que minha leitura foi feita primeiramente a partir dessa versão impressa.

${ }^{5}$ Peter, na obra ficcional, conhece Maria pessoalmente. Fora da ficção, Paul Auster e Sophie Calle também têm contato, o que leva ao seu trabalho colaborativo em Double Game e Gotham Handbook.
} 


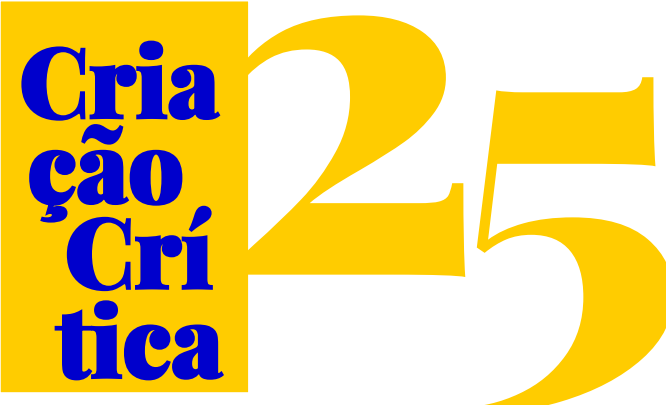

Em passagens como o agradecimento à artista francesa, que aparece em Leviatã e retorna modificado na obra de Sophie Calle, observa-se esse movimento. Isso porque, no verso da contracapa de Jogo duplo, encontram-se os dados catalográficos do livro e mais um recado: "A autora agradece em especial Paul Auster por permitir misturar ficção e fato" (CALLE, 2007, s/p.).

Esses dois lados da mesma página contêm trocas importantes: os nomes dos autores (ou melhor, que nome ocupa a posição autor) e a ordem de duas palavras-chave. Paul Auster fala de fato e ficção, enquanto Sophie Calle usa a expressão em ordem inversa. Dois movimentos, portanto. Isso condiz com a ordem escolhida para a organização desse jogo duplo, a qual se traduz nos capítulos do livro: "I - A vida de Maria e como influenciou a vida de Sophie"; "II - A vida de Sophie e como influencia a vida de Maria"; "III - Modos de misturar fato e ficção, ou como tentar se transformar em uma personagem".

O tamanho da folha também é reduzido em comparação às outras folhas dessa edição, o que marca o formato escolhido para a reprodução das páginas de Leviatã que formam a primeira parte de Jogo duplo - seu suplemento - e o distingue das três partes principais que a compõem. O resultado é uma espécie de colagem do trecho daquela publicação nesta. Entretanto, não se trata apenas de uma reprodução das páginas 60 a 67 do romance de Auster. Trata-se de uma intervenção também, levando-se em conta as alterações (em caligrafia vermelha) operadas por Sophie.

\subsection{Vida de Maria, diário de Sophie}

Logo após a dupla de dados catalográficos e agradecimentos, há uma introdução ao Jogo duplo: "as regras do jogo" ("the rules of the game") (CALLE, 2007, p. 1). Pela posição e forma desse parágrafo, em vermelho, essas regras poderiam ser tomadas como epígrafe. Segundo Calle, as regras do jogo estão nas oito páginas de Leviatã em que são descritos "episódios de sua vida" (2007, p. 1). Depois dessa breve aparição, Maria a teria deixado para viver sua própria vida. Intrigada por esse duplo, ela decidiu transformar o romance de Auster em um jogo e fazer sua próxima mistura de realidade e ficção.

Avaliando esse propósito de mescla como um projeto, feito em colaboração entre o escritor e a artista, percebe-se a importância da palavra, seja na criação das histórias, seja como elemento visual. O romance de Auster serve, nesse sentido, como base para uma escrita que propõe tornar-se múltipla manifestação artística. É um guia para a criação de outras histórias e de outros objetos. Esse jogo, entretanto, inicia por certa subversão das regras.

A primeira página de Leviatã inserida nesse livro, após o nome do autor, título e editora, inicia com uma frase cortada no meio, já que o que a completa está na página anterior, deliberadamente omitida ${ }^{10}$. A primeira palavra na p. 60 é "contatos)", fechada por um parêntese apenas de um lado, separando-a do resto da frase e, ao mesmo tempo, deixando-a ainda conectada ao que veio antes, ao qual o leitor não tem acesso, nesse caso. Para a leitura do que a precede, exige-se um leitor investigativo, ou com uma memória que possa recriar palavras lidas em algum

\footnotetext{
${ }^{9}$ Em inglês: "The author extends special thanks to Paul Auster for permission to mingle fiction with fact".

${ }^{10} \mathrm{O}$ resto da frase está omitido porque encontra-se na página 59 de Leviathan, a qual não foi incluída em Double Game. Nesse sentido opera-se um corte ou, como se diz em inglês, "p. 59 didn't make the cut". Isto é, não sobreviveu ao processo de eliminação.
} 


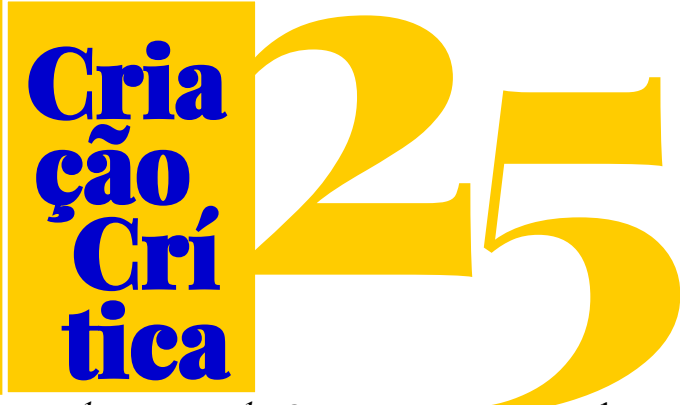

momento do passado - algo bastante reminiscente de Pierre Menard, o autor de Quixote, um conto de Jorge Luis Borges (1944).

O que se segue é uma menção à vida amorosa de Maria, envolvida, nesse momento com Peter, o narrador-protagonista. Essa passagem, porém, é obscurecida ou interrompida por duas palavras que se sobrepõem a esses dois primeiros parágrafos. Em caligrafia vermelha, como todas as inserções de Calle nesse trecho, lê-se "Hello Maria" (AUSTER, 1992, p. 60 apud CALLE, 2007). Essas palavras, portanto, em parte cobrem o texto em fonte tradicional e cor preta, ao mesmo tempo em que o deixam transparecer e ser lido.

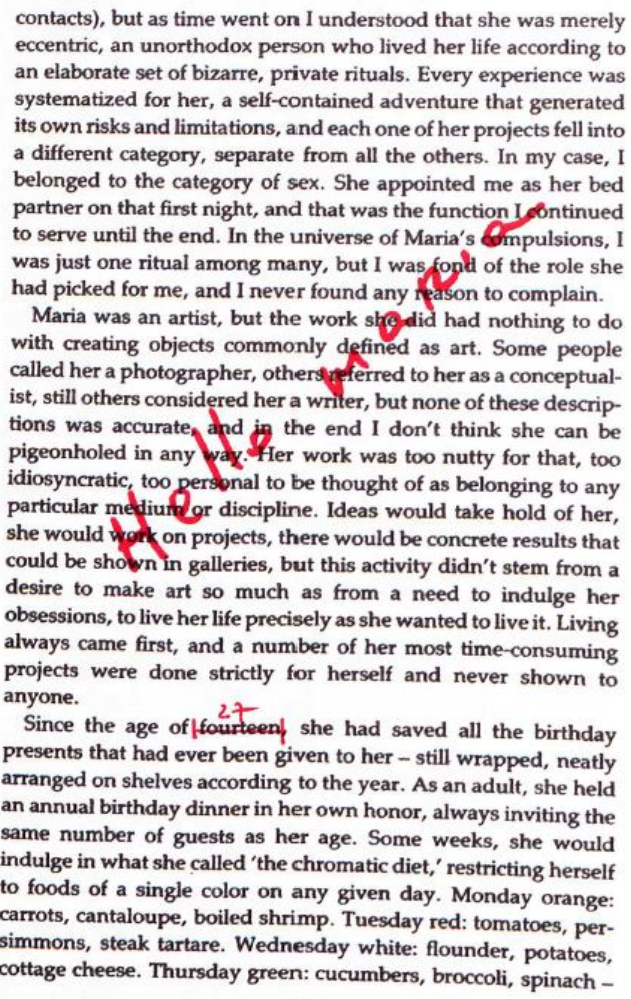

60 and so on, all the way through the last meal on Sunday. At other times, she would make similar divisions based on the letters of the alphabet. Whole days would be spent under the spell of $b, c$, or $w$, and then, just as suddenly as she had started it, she would abandon the game and go on to something else. These were no more than whims, I suppose, tiny experiments with the idea of classification and habit, but similar games were just as likely to go on for many years. There was the long-term project of dressing Mr L., for example, a stranger she had once met at a party. Maria found him to be one of the handsomest men she had ever seen,excossive! but his clothes were a disgrace, she thought, and so without announcing her intentions to anyone, she took it upon herself to improve his wardrobe. Every year at Christmas she would send him an anonymous gift - a tie, a sweater, an elegant shirt - and because $\mathrm{Mr} \mathrm{L}$. moved in roughly the same social circles that she did, she would run into him every now and again, noting with pleasure the dramatiç changes in his sartorial appearance. For the fact was that Mr L. plways [wore the clothes that Maria sent him. She would even go up to him at these gatherings-and compliment him-on what he was wearing, but that was as far-as-it-went, and he never caught on that she was the one responsible-for-those Ghristmas packages.

She had grown up in Holyoke, Massaehusetts, the only child of parents who divorced when she was [six| After graduating from high school in 1970, she had gone down to New York with the idea-of attending art-scheol-and beeoming a painter. but she lost interest after one term and dropped out. She bought-herself-a secondhand Dodge van-and took off on a tour of the Ameriean centinent, staying for-exaetly-two-weeks in pach-state, finding temporary work along the way whenever possible - waitressing jobs, migrant farm jobs, facteryjebs, earning just enough to keep her going from one place to the next. It was the first of her mad, compulsive projects, and in some sense it stands as the most excessive extraordinary thing she ever did: a totally meaningless and again arbitrary act to which she devoted almost twwo years of her life. Heronly-ambition wastospend fourteen-days-in every-state, and

61

Figura 1: páginas 60 e 61 de Leviatã em Jogo duplo.

Ao longo das próximas páginas encontram-se diversas outras intervenções de Sophie. Tratam-se, principalmente, de cortes e inserções (enxertos) de palavras e de comentários. O primeiro corte e inserção altera o numeral que informa a idade em que Maria resolve começar um experimento: "desde os 14 anos ela guardava os presentes de aniversário que ganhava" (Ibidem). Acima do "14" riscado, porém visível, a palavra "27" é escrita. No trabalho The Birthday Celebration ("Celebração de aniversário"), incluído na segunda parte da obra, Sophie diz que começou essas festas e a guardar os presentes em 1980. Convidava o número de pessoas correspondente à idade que estaria fazendo. Parou com 40 anos. Na seção dedicada a essa "exposição íntima", cada página corresponde 


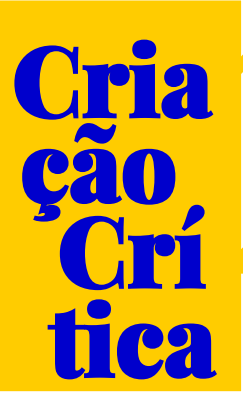

Da mesma forma, Calle risca, a seguir, as palavras dramática e sempre: em vez de dramáticas mudanças, pequenas; em vez de o Sr. L sempre usar as novas roupas que Maria lhe dera em segredo, ele às vezes as usava. Quando Peter descreve como ela ia conversar com ele onde o encontrasse e o elogiar pela aparência, todo esse trecho, somando quatro linhas, é cortado e, por isso, deixado de fora. Não seria necessário lê-lo, mas a curiosidade ligada ao que é parcialmente velado é atiçada. Joga-se, também, com as expectativas do leitor.

Adiante, Peter descreve detalhes acerca da vida pessoal de Maria. Todas as informações específicas sobre sua idade, origem, formação universitária, assim como a decisão de viajar por um tempo são cortadas e, por cima delas, adicionadas alterações: nasce em Paris, pais divorciados aos três anos de idade, não conclui um curso universitário, torna-se uma andarilha. Viaja de país em país, por mais ou menos sete anos, trabalhando temporariamente em cada lugar. Quando Peter fala de um de seus primeiros "loucos projetos compulsivos", ela apenas corta a palavra loucos. Sublinha, também, a descrição desse projeto como algo extraordinário, sem sentido e arbitrário. À margem, Calle escreve: "excessivo novamente" (2007, p. 61 do suplemento dentro de Jogo duplo).

Depois de viajar, elas retornam para casa: Maria para um apartamento em Nova York, Sophie para a casa do pai em Paris. Aí, começam a seguir estranhos nas ruas, a tirar fotos deles e escrever histórias que imaginavam para eles. Outros projetos se seguiram com uma constante, "seu interesse era o olho, o drama de ver e ser vista" (AUSTER, 1992, p. 63 apud CALLE, 2007).

$\mathrm{Na}$ versão de Auster, Maria contrata um detetive particular por alguns dias para segui-la pela cidade. Nessa versão de Sophie Calle, ela pede à mãe que a siga por uma semana. Apesar de artificial, o exercício tornava pequenas ações e hábitos mecânicos em algo carregado de sentidos. Ao final, veio a sensação de tornar-se uma estranha, um ser imaginário, frente ao olhar do outro e, agora, à análise que poderia fazer de seus próprios movimentos gravados em fotos. Essa sensação foi levada ao extremo em seu próximo projeto, em que decide seguir um estranho até Veneza. Vários cortes, nesse trecho, substituem os detalhes dados por Peter por correções de Sophie: vai de trem à Veneza, compra uma peruca loira e o segue de volta à Paris, todo o tempo usando um diário para escrever sobre seus movimentos. O sentimento, agora, era de vazio, como se tirasse fotos de coisas que não estivessem lá. A câmera transformara-se em uma forma de fazer o mundo desaparecer (em vez de aparecer), uma técnica para encontrar o invisível.

Desesperada para desfazer esse processo, Maria se envolve em um novo projeto. Trabalha em um bar topless por uma noite. Nesse ponto, os cortes e inserções de Sophie modificam mais drasticamente a experiência. Trata-se, para ela, de um "boteco de strip-tease" (CALLE, 2007, p. 65 do suplemento), em vez de um bar. Ela trabalha por um mês, não uma semana, e pede para um amigo fotografá-la por uma noite, o que se torna a exposição intitulada Striptease (na versão de Auster: "A Dama Nua"). Além disso, nas anotações em vermelho de Sophie, lê-se que a descrição de Peter sobre seu belo corpo é "lisonjeira" e a do jeito como dança, movendo-se de forma bastante sensual e provocadora, é "exagerada" (CALLE, 2007, p. 65 do suplemento). Assim, não apenas reconta a experiência de forma mais crua e mais complexa - o tempo é mais longo, o local é mais realista recorrendo a menos eufemismos, mas também recorta a parcela sensual que acaba por idealizar o corpo feminino, resumindo-a em uma expressão: um exagero. 


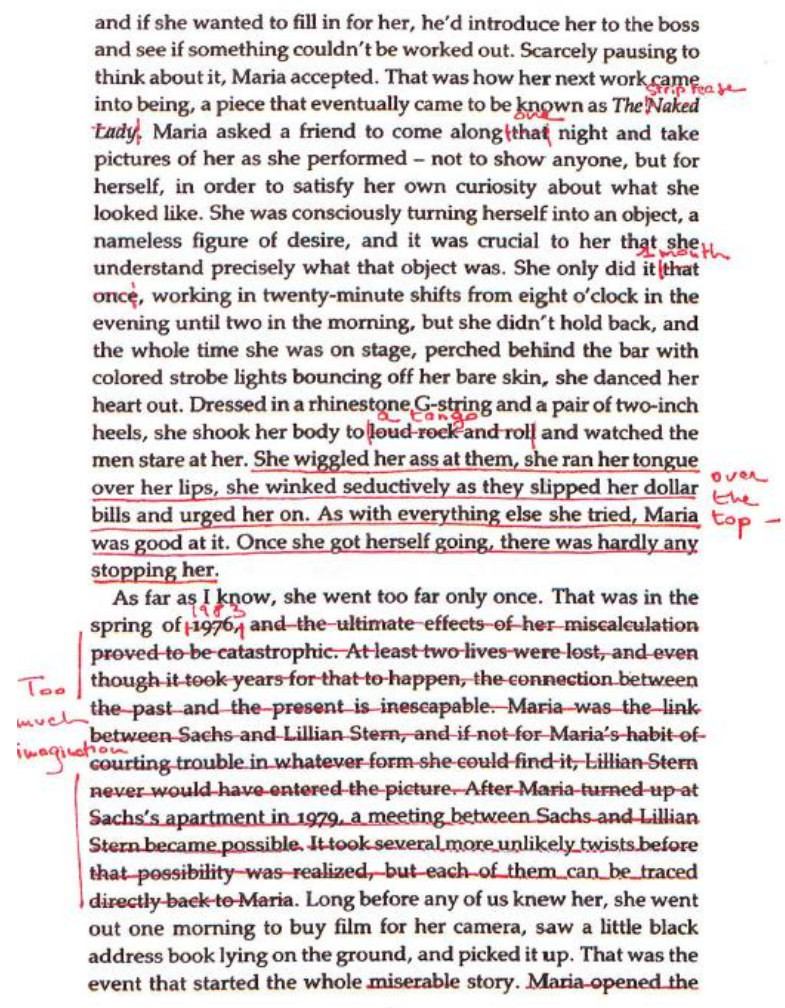

65

Figura 2: p. 65 de Leviatã em Jogo duplo.

O próximo parágrafo sofre o mesmo tipo de mudança e é em grande parte também riscado. À margem, mais uma vez, a razão: "muita imaginação" (CALLE 2007, p. 65 do suplemento). Sobram a primeira e as últimas frases, que relatam a vez em que Maria "foi longe demais" (CALLE, 2007, p. 65 do suplemento), ao encontrar um caderno de contatos na rua. Havia mais ou menos 400 nomes lá, com endereços e telefones. Um detalhe interessante: as várias alterações nos dados contidos nesse caderno mostravam que havia pertencido ao dono por um bom tempo. Entende-se, portanto, que a ação de riscar nomes e informações e substituí-las por outras precede o que é feito, nesse momento, no prefácio de Jogo duplo. Essas operações não só se tornam matéria para Leviatã, mas ocorrem na construção da forma da obra atual de Sophie ${ }^{12}$.

Um dos últimos trechos riscados fala da intenção de Maria em devolver a caderneta para o dono. Ao lado da última palavra, é adicionado: "mas ela fez uma cópia antes" (CALLE, 2007, p. 66 do suplemento). No entanto, dessa vez o traço que antes cobria frases inteiras da versão de Auster, transforma-se em pontilhados sobre suas palavras. Parece ser um tipo mais suave ainda de sobreposição. Quando Maria decide começar uma busca pelos nomes escritos no caderno, o relato termina, mais uma vez pela interrupção da última frase. Sobre essa última página, um "adeus Maria" (CALLE, 2007, p. 67 do suplemento) ampliado e escrito em diagonal.

\footnotetext{
${ }^{12}$ Além disso, The Address Book (2012) torna-se outra publicação de Sophie Calle, em que mais uma vez traz em textos e fotos o diário de suas experiências com o objeto encontrado. Dessa vez, porém, foi contatada pelo homem que supostamente teria sido o dono do caderno de endereços, o que a levou a jurar que não relançaria o livro até depois da morte dele.
} 


\subsection{As regrous do jogo duplo}

A introdução à seção seguinte (parte 1 de Jogo duplo), retoma a ideia de que, em Leviatãa, Maria passa pelos mesmos rituais que Sophie. Entretanto, nesse texto, Paul Auster teria inserido alguns detalhes de sua própria invenção, segundo Sophie Calle. De forma a aproximar-se da personagem, ela diz ter decidido seguir "as regras do livro"13.

Há regras, no entanto, que não estão claramente expressas no romance de Auster, mas que podem ser percebidas pela forma como Jogo duplo é organizado. O mais aparente guia para isso são as alterações de corte e inserção descritas previamente. Afinal, pode-se interpretar o desaparecimento de Sachs, em Leviatã, como um corte na narrativa, e o projeto de escrever o livro deixado por ele como uma operação de articulação com a versão prévia, além de adição de um novo texto. Ainda em relação a de Sachs, observa-se que seu corpo desapareceu não apenas devido a sua morte, isto é, em um sentido mais metafórico, mas, pela causa de sua morte - a explosão da bomba que construí pode-se presumir que a materialidade de seu corpo sofreu da mesma forma esse efeito de apagamento, e mesmo de separação. Além disso, percebe-se a importância do funcionamento dos nomes próprios nessas obras, assim como a experimentação com palavras e imagens, como a divisão de dias baseada em cores e letras do alfabeto.

Já foi citado o caso de Benjamin Sachs, cujo nome faz lembrar o do autor, porém em Jogo duplo as relações entre os nomes próprios dos personagens e dos escritores/artistas - Paul, Maria, Sophie - também é relevante. Se forem estabelecidas funções para cada participante nessas obras, vêse que, em Leviatã, Paul Auster ocupa a posição de autor, Sophie Calle é a referência externa, ou modelo, enquanto Maria é a criação, a personagem baseada nessa modelo. Em Jogo duplo, Sophie ocupa a posição de autora, enquanto Auster é uma referência externa (como autor de Leviatã), mas Maria, agora, é a modelo, a inspiração. Contudo, quem ocupa o lugar de personagem, nessa nova equação, não é ela. E, como se disse, essa nova personagem tem como modelo outra figura da ficção, Maria. Trata-se, nesse caso, de referências tanto intertextuais quanto intratextuais (já que Maria reaparece no suplemento de Leviatã em Jogo duplo). Ainda assim, envolve algo que está fora do texto, além do alcance, ainda que não se fale mais da ficção baseada em fatos reais. A performance em turbilhão de Leviatã, que envolve fato e ficção pode levar à sua mescla, como propõe Sophie Calle em Jogo duplo.

Essas relações entre os nomes nas obras, portanto, criam pelo menos duas triangulações. Pode-se perguntar, por isso, quem é a nova personagem criada por Sophie Calle. As fotos na obra têm ela como modelo, enquanto ela diz se aproximar da personagem Maria. Sophie ocuparia, dessa forma, a posição de autor e também a de personagem. Faz dessa uma obra de certa forma autoficciona $1^{14}$, porém, no momento em que se torna personagem, não é mais Sophie, a autora. Quando se torna objeto da própria escrita e modelo das próprias fotografias, já é outra.

\footnotetext{
${ }^{13}$ Aqui usa a expressão "to go by the book", um jogo de palavras, ou duplo sentido, que combina com o título "jogo duplo" com os "duplos" desses livros. Isso porque pode-se entender a expressão no seu sentido mais cotidiano de "seguir as regras", ou pode-se perceber o "livro" (book), nesse caso, como Leviatã, e a vida ficcional de Maria como as "regras do jogo".

${ }^{14}$ Usa-se a expressão "autoficção" aqui no sentido trabalhado pela professora Eurídice Figueiredo, em Mulheres ao espelho: autobiografia, ficção, autoficção (2013): uma espécie de romance pós-moderno que apresenta autorreflexividade e que questiona as próprias categorias de verdade e mentira, "mostrando o quão construída é toda autobiografia" (FIGUEIREDO, 2013, p. 11), com formatos inovadores.
} 
Nesse sentido, a duplicação, ou o duplo, implica um terceiro, como diria Lacan (O seminário, livro 8, 1960-1961). Ao falar de agalma, um ornamento, ou enfeite, mas com valor de enigma, explica que, para entrar em jogo "o outro", não vai haver apenas um, mas dois outros. "Em outras palavras, no mínimo eles são três" (1992, p. 140). Isso porque, talvez o que desejamos é desejar, ou o mistério, o que não temos. De certa forma, quando se colocam os nomes de Maria e de Sophie ao mesmo tempo em Jogo duplo, surge uma impossibilidade: a de sua convergência em um mesmo, uma mesma mulher ou personagem. Apesar de duplos, elas têm existências textuais e visuais diferentes, posicionando em papéis e espaços diversos. O que acontece é uma multiplicação desses papéis, ou um possível desdobramento do nome Sophie conforme as posições que ocupa.

A partir das relações entre esses nomes e do trabalho de manipulação do prefácio, ou melhor, do suplemento nessa obra, percebe-se não apenas a continuidade de um trabalho colaborativo entre os dois artistas, mas a criação de diversos duplos (e múltiplos, portanto), próxima ao jogo com nomes próprios realizado por Auster em diversos de seus romances (entre eles A Trilogia de Nova York, 2004, e Invisível, 2009). Com esses jogos de palavras, pode-se pensar na arbitrariedade da nomeação de objetos. Há estudos sobre essa problemática como os de Michel Foucault em As Palavras e as Coisas (2000) e Isso Não é um Cachimbo (2004), em que analisa obras de René Magritte, como A Traição das Imagens (1928-29). Nelas, há provocações a partir de contradições criadas na disposição da obra. O cachimbo que se vê é dito não cachimbo. Um ovo é chamado de chapéu, e assim por diante. Fala-se, enfim, da diferença existente entre um nome e uma coisa, mas também entre o que vemos na arte e o que isso diz sobre nossa forma de ver o mundo. Na interpretação de uma representação visual não se pode tomar a imagem pela coisa a qual se refere, até porque o modelo pode ser apenas uma ideia abstrata, uma representação mental, sem forma fixa.

Há ainda a complicada utilização do nome próprio em obras literárias. Michel Foucault, Paul Ricour, Roland Barthes, Walter Benjamin, entre outros teóricos, já abordaram a questão do autor, ou posição autor, da relação de ausência e presença que isso envolve; daquele nome, na obra, que se refere a alguém, um corpo, que não está lá presente, mas que deixa essa marca, essa função. Em casos de obras com traços autobiográficos, como as de Auster e Calle, isso se torna ainda mais complexo. É como se retornássemos de alguma forma à questão colocada por Magritte quando apresenta a pintura de um cachimbo. Dessa vez, porém, não vemos o desenho do objeto e seu nome junto à negação logo abaixo. Vemos Calle como modelo, sentada em um túmulo de cemitério, com o pai ao lado, ou com uma peruca loira, cercada por animais de pelúcia, exemplos da primeira parte de Jogo duplo.

Nessas obras, portanto, há uma série de duplos e, com isso, um pensamento sobre a própria série, envolvendo a repetição, mas também a diferença, como na arte modernista de Andy Warhol e de Marcel Duchamp. Pensa-se, ainda, na era da reprodutibilidade técnica, comentada por Walter Benjamin (1936/1996), ou no jogo de leitura presente em Um Lance de Dados (1897), de Mallarmé. Há duplos, ainda, em obras como William Wilson (1839), de Edgar Allan Poe, ao qual Paul Auster faz referência na Trilogia. Mas há, também, o tipo de trabalho artístico múltiplo, como Jogo duplo, que não é nem isso nem aquilo, em termos de classificação, ou gênero, como diz Peter, em Leviatã. Nem só literatura, nem só fotografia, nem só experimentação, ou instalação, ou arte conceitual. Para Sophie, ou para Maria, é a vida que vem primeiro, o que faz pensar que a arte vem depois. No caso de Jogo duplo, entretanto, a arte também pode vir primeiro e a vida/experimentação artística depois. Pode-se partir da arte de Sophie Calle, construir a ficção de Maria e então tomá-la como inspiração para outras experimentações com objetos, cores, palavras, fotografia.

Inversões, portanto, mas também deslocamentos. É por isso que a dupla fato/ficção não se encerra na oposição. Chega-se no limiar ou no extrapolar da fronteira entre ficção e realidade na 


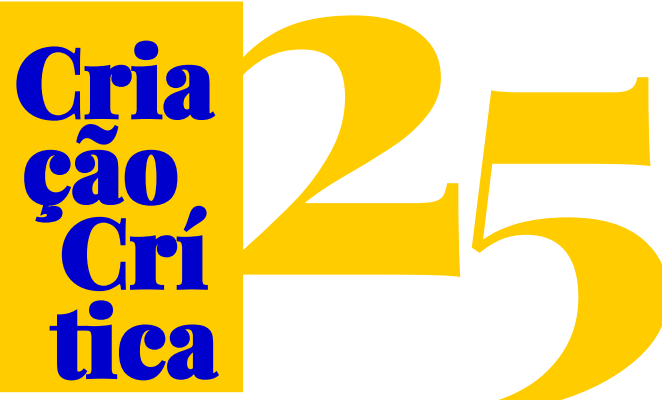

criação dessas histórias e personagens. Em Leviatã, Benjamin também escreve um romance, The New Colossus (O novo colosso). É um romance histórico baseado em "fatos documentados e verificáveis" (AUSTER, 1992, p. 41). Estabelece-se, aí, quão verdadeira pode ser a fícção - o que pode diferir de sua verossimilitude -, e que porção de verdade pode existir nos fatos.

As contribuições de Jacques Derrida para essa discussão são muitas. Ele escreve acerca da desconstrução e da diferença, do nome próprio unido e divido, e do fazer em um texto o que se fala nele. Em Gramatologia (1967), Derrida comenta o uso do nome de Jean Jacques Rousseau em Confissões (1782). Ele afirma não ser preciso pensar conjuntamente a experiência e a teoria rousseaunianas da escritura, o acordo e discordância que, sob o título de escritura, relacionam Jean Jacques com Rousseau, unindo e dividindo seu nome próprio ${ }^{15}$. Conecta-se a isso o que o teórico chama de esquivança na própria fala experimentada por Rousseau.

Diz Derrida que, do lado da experiência, vê-se o recurso à literatura como reapropriação da presença, ou seja, da natureza. Do lado da teoria, a palavra simplesmente parece dar conta da unidade desses dois gestos. Sendo a fala a forma de instituição ou de convenção mais natural para significar o pensamento, se adiciona à escritura, se junta como uma imagem ou uma representação. Nesse sentido, não é natural. Por isso Derrida diz que o suplemento é perigoso. É a adição de uma técnica, de uma espécie de astúcia artificial e artificiosa para fazer presente a fala quando, na verdade, está ausente.

O conceito de suplemento que, segundo, determina o de imagem representativa, abriga em si duas significações diferentes. O suplemento se adiciona, é um excedente (como a prótese), uma plenitude que enriquece outra plenitude, acumula a presença.

É assim que a arte, a techné, a imagem, a representação, a convenção, etc., vem como suplemento da natureza e são ricas de toda essa função de culminação. Esta espécie de suplementaridade determina de uma certa maneira, todas as oposições conceituais nas quais Rousseau inscreve a noção de natureza na medida em que deveria bastar-se a si mesma. (DERRIDA, 1973, p. 177-178)

Porém, o que coexiste, junto a essa descrição, é sua significação como algo que supre. $O$ suplemento se acrescenta para substituir e "intervém ou se insinua em lugar de" (DERRIDA, 1973, P. 178). Se representa uma imagem, é "pela falta anterior de uma presença" (ibidem). Como indica a palavra, é um suplente, um adjunto, uma "instância subalterna" que "tem-lugar", ou toma lugar. Está marcado por um vazio. É exterior ${ }^{16}$, ou "adição exterior" (ibidem).

\footnotetext{
${ }^{15}$ Em Gramatologia, Derrida trata dessa divisão do nome próprio do autor de Confessions para falar da busca, que se pode empreender na leitura, pelo significado do que Rousseau quer dizer no texto. O teórico afirma que o significado, entretanto, é a própria escritura. Da mesma forma, não se deve buscar a "verdade significada" por estes escritos, ou então a "vida de Jean Jacques atrás de sua obra" (DERRIDA, 1973, p. 184). Esse corte do nome próprio serve, ainda, para pensar o próprio do nome (propriedade, reapropriação) e poder ser relacionada às operações de divisão e criação de nomes próprios desenvolvidas por Auster e Calle.

${ }^{16} \mathrm{O}$ suplemento tomado como exterior parece aproximar-se, ainda, da ideia de borderline, ou linha divisória, fronteira entre dois espaços, duas pessoas, dois textos; e, por isso, borda, margem, rodapé, como no texto de Derrida, Survivre. Além disso, pode-se entender o exterior como lugar de um outro ou de um estrangeiro. Como se disse, em Paris, 1976, Wills trabalha com duas línguas, cada uma estrangeira em relação a outra, sem determinar uma origem do texto. Há ainda, porém, a noção de alteridade que passa pela própria figura do estrangeiro - ou estrangeira: Maria Turner, em Leviathan; Calle em suas viagens pela América comentadas em Double Game. Assim como o suplemento, o estrangeiro é aquele que "está a mais", segundo Julia Kristeva (1994, p. 11). Além disso, viver com o outro é "estar em seu lugar" (Ibidem, p. 21), é fazer-se outro para si mesmo. E, por que não, também uma instância subalterna. Kristeva vê esse limiar, borderline, como
} 
Para Derrida, a diferença (différance) é o que torna possível a oposição presença/ausência e, pode-se entender, a coexistência desses elementos contrastantes. Isso ocorre pois ela produz o que proíbe, torna possível o que torna impossível (1973, p. 176). É o que o teórico chama indecidível. A partir desse lugar do indecidível é possível pensar Jogo duplo e o trabalho de articulação de Paul Auster e Sophie Calle. Articulação e divisão, na verdade. Afinal, como afirma David Wills (1995), é apenas através da autodivisão, da separação, que o corpo pode se tornar língua, que a palavra pode nascer. Contudo, essa ideia pode ser levada no sentido oposto, de que é somente quando se torna um corpo maleável ou divisível, pronto para a amputação, que a palavra pode inaugurar o processo pro(s)tético ${ }^{17}$.

Se esse texto não pode ser considerado como um todo, mas como uma articulação entre partes, incluindo vazios e aberturas, seria preciso, como sugere Roland Barthes, em $S / Z$, "estimar de que plural é feito" (BARTHES, 1992, p. 39). Barthes descreve o que pode ser escrito (reescrito), como o escrevivel, um tipo de texto difícil de ser encontrado, pois suprime a crítica, que se confundiria. Isso parece ser o que acontece, até certo ponto, em Jogo duplo. Não suprime totalmente a crítica, porém certamente pode confundir o público leitor. Sophie Calle faz, nesse texto, o que poderia ser chamado de "escrevivido"18. Uma escrita do eu, que se volta, talvez com mais intensidade, para o outro.

Nessa mesma direção, David Wills refere-se, em Prosthesis, a uma certa "mescla de vida, escritura e margens", à escrita no acontecer da prótese, e à prótese como uma "matéria viva" (1995, p. 133), um texto, tecido ou pele. Faz, como Sophie Calle, inserções: comentários, notas e anedotas. Nesse caso, inserções em um dos textos, em uma língua (inglês ou francês), que não existem no outro, e vice-versa. Elas se tornam, desse modo, também omissões, dependendo de que ponto se parte na leitura. Explica detalhes que são particulares àquela língua, ambuiguidades por vezes intraduzíveis.

Segundo Wills, o texto como prótese não consegue preservar a unidade de um gênero. É mais uma vez indecidível. Por isso a articulação de gêneros textuais ou formas artísticas em Jogo duplo é estranha, ao primeiro olhar, mas bastante compreensível na aproximação, na leitura como jogo. Isso porque trabalha com o que Wills chamada de rede significante de "duplicação, substituição, transferência, articulação, invenção, desordem" (1995, p. 169). Faz-se, então, uma mistura, entre fato e ficção, dentro e fora, que pode acarretar uma indistinção de níveis de leitura: entre o que é fatual, o que é literal, o que é paródico, por exemplo. Se se pode falar, nessa obra de Sophie Calle, em traços autobiográficos, pode-se falar na biografia da personagem Maria ${ }^{19}$. Esses corpos nunca são

traço característico de um personagem como Meursault, de Albert Camus (O Estrangeiro, 1942). Ele é borderline porque beira a psicose. Sua namorada, Marie, cujo nome Maria ecoa, também foge ao tradicional e, como a Maria de Leviathan, desaparece da trama à medida que o narrador deixa de pensar sobre ela.

${ }^{17}$ Curiosamente, a língua portuguesa também admite duas versões da prosthesis: prótese e próstese (a segunda razão para a inclusão entre parênteses do "s" no título desse artigo). Apesar de "próstese" ser pouco usada, também se conecta aos sentidos de "aplicação, adição" (segundo o Dicionário Priberam de Língua Portuguesa).

${ }^{18}$ A escritora brasileira Conceição Evaristo trabalha com a ideia de escrevivência para pensar a conexão entre a vivência e a escrita, em especial em relação à condição social da mulher negra, como ela explica em uma entrevista a Juliana Domingos de Lima, em 2017. As noções de escrevivência e de escrevivido, portanto, apesar de diferentes, sobretudo pelas implicações sociais da primeira, aproximam-se por propor a leitura de ficções aliadas à vivência ou a sobrevivência.

${ }^{19}$ Em Double Game, na sessão intitulada "Celebração de aniversário", veem-se presentes guardados dentro de um armário envidraçado. Esta seria uma das obras de Sophie Calle que teria inspirado Maria Turner, em Leviathan. Por sua composição, algumas dessas vitrines de presentes lembram a obra O Grande Vidro (1912 a 1923), de Marcel Duchamp. É possível ler nessa relação, porém, ainda outra. Em Maria con Marcel: Duchamp em los trópicos, Raúl Antelo menciona o relacionamento entre Duchamp e Maria Martins, artista brasileira, e discute o vínculo entre suas obras. A partir de uma abertura que Duchamp faz na parede próxima a Grande Vidro, no museu da Filadélfia, pode-se ver a escultura de Maria Martins intitulada Iara - Não te esqueças que venho dos trópicos (1942). Para Raúl Antelo, essa escultura, como suplemento 


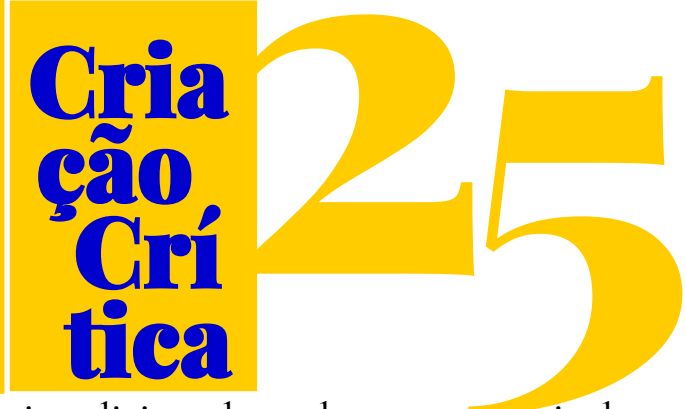

completos, nunca integrais, mas estão em busca de algo que seja adicionado a eles, que se articule nesses espaços vazios, como a margem, sem nunca os preencher totalmente. Um suplemento, talvez. Uma prótese, um outro corpo, outro texto e outro nome.

\section{Algumas considerações sobre corpos pro(s)téticos}

Em Prosthesis, ao discorrer sobre a perna mecânica do pai, Wills desenvolve uma reflexão sobre a artificialidade do natural e a naturalidade do artificial. Se, por um lado, a prótese é construída tomando como modelo uma perna orgânica, na amputação, por outro lado, o médico toma a perna mecânica como parâmetro para realizar o corte. Depende-se dela, portanto, para a operação. Essas vias opostas de alguma forma precisam conectar-se para coexistirem. Outros diversos exemplos podem ser relacionados a essa mesma condição: os duplos, pares em oposição, como ausência/presença, natureza/arte, dentro/fora.

Assim, como já se disse, o texto, como corpo, é prótese na medida em que ao escrever, escrevese prótese. Aí transitam, outra vez, natural e artificial. O corpo carrega ambos e leva ao limite suas significações, confundindo-as, operando, cada vez mais, a partir de formas híbridas. Usamos próteses, afinal, e tornamo-nos também prostéticos nesse sentido.

Em Prosthesis, encenam-se, portanto, deambulações por diferentes espaços discursivos, mas retorna-se, com a voz autoral, repetidamente a esse local familiar, à casa da infância e à prótese paterna. Volta-se, ainda, aos textos de Derrida, ao sobreviver às margens, ao artista que anda à beira do abismo, e a imagens como a de amputados de guerra à procura de caridade em um metrô em Paris, em 1976. Volta-se, mas no sentido de voltar-se, de uma torção, duplicação, que ocorre, como explica Wills, ao nível da palavra.

O familiar atrai todos os discursos sobre o corpo, relativo às funções corporais e também à fisicalidade da palavra, seus efeitos fáticos e poéticos. E é por meio do discurso sobre o corpo que a palavra demonstra a extensão de sua diferença, tomando emprestado por um lado o tom de tudo que é próprio e presente, tudo que pode ser dito na intimidade de uma presença plena e espontânea, e por outro lado a dimensão do ultrajante, obs-cena, tudo que é excluído do círculo familiar, do circuito familiar de decência. (WILLS, 1995, p. 139)

Daí haver, segundo ele, outras poses, ou posições, para a palavra, como aquela em que a palavra se torna corpo, não através da nomeação, mas através da subscrição a modelos de corporeidade. Retoma-se, assim, uma ideia inicial: é através da autodivisão, da separação, que o corpo se torna palavra, assim como é somente quando o corpo se torna maleável, ou divisível, pronto para a amputação, que a palavra pode inaugurar o processo prostético (WILLS, 1995). A própria palavra como corpo não pode garantir sua integridade.

Por isso, o texto-prótese, como o corpo, envolve articulação e esta, por usa vez, implica divisibilidade. Corpo, ou corpus, em Jogo duplo. Corpo de Sophie, de Maria, corpo da palavra, corpo do texto. Divisão do nome próprio em Paul / Benjamin / Auster, mas divisão e articulação também entre

do Grande Vidro é, na realidade, "uma figura feminina que emerge, por um lado, de uma fonte, um Fountain, mas sai de uma apropriação antropofágica, não menos ready-made que Fountain" (2006, p. 24, tradução minha). Assim, a Maria Turner de Double Game, é, em diversos sentidos, a figura feminina que torna, que emerge, como Iara, de um suplemento. 


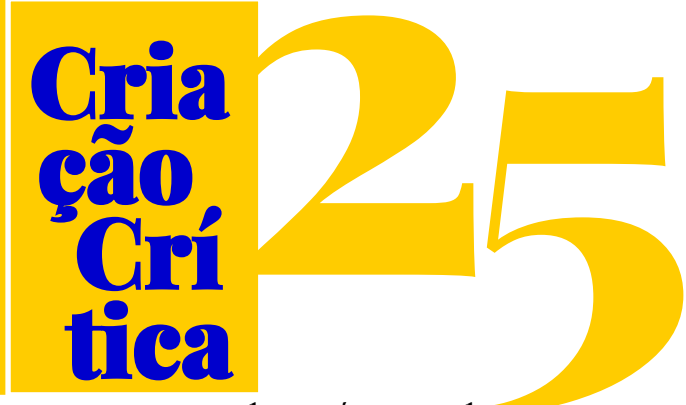

Sophie e Maria. Não só isso como a vontade de preencher espaços vazios das páginas de Leviatã, escrever às margens, envolvendo operações cirúrgicas de corte, enxerto e articulação. A própria divisão entre Leviatã como prefácio, ou suplemento, e o resto do livro, assim como sua diferente formatação, torna esse texto também prótese.

No texto-prótese, além disso, pode haver um uso e não simplesmente uma menção da coisa. Essa característica também pode ser pensada em relação ao texto autorreferencial, ou metaficcional, e implica uma mistura fato/ficção na autoficção ou autobiografia. Como explica Wills, mesmo quando tradicionalmente se imagina que o texto se refere a um exterior real ou a um autor vivo que produz palavras, ele consistiria "em uma espécie de mistura das assim chamadas coisas naturais e artificiais, do humano e do não humano" (WILLS, 1995, p. 135).

Os trabalhos aqui apresentados são, nesse contexto, trabalhos de articulação: articulam-se diferentes artes - ou artes mistas - e multimídias. Articulam-se Auster e Calle, para o desenvolvimento de seus projetos, cujos desdobramentos multiplicam a noção de corpo. Amarram-se, por fim, leituras de obras teóricas complexas, como são as de David Wills e de Jacques Derrida, para falar da dupla palavra-imagem, e do suplemento-prótese, da diferença na escritura e da escritura que opera diferença.

Para falar do corpo, na obra de Sophie Calle, é necessário colocar-se como observador de suas fotos. É preciso, portanto, observá-la como modelo, ler a escrita de Sophie autora, presenciar a ficção de sua vida nas fotos em preto e branco. Em algumas dessas fotos, porém, há o corpo seminu, o Striptease. Avançamos, então, em alguma intimidade, entramos parcialmente em cena, e é possível que, nesse movimento, a dimensão obs-cena também seja considerada. A sedução é a sedução da imagem, do corpo, mas também daquela tentativa de desvendamento de um mistério, de uma verdade, que frequentemente sentimos na leitura dos vários tipos de ficção.

O próprio método comparativo de associação, ou articulação, utilizado nessa análise e em tantas outras, é uma espécie de cadeia protética, para Wills (1995), e assim "indiscriminadamente contágio e promiscuidade" (WILLS, 1995, p. 169). Mistura, desse modo, sem reservas, sem o medo de tornar "impuros" diferentes textos, gêneros e corpos. Costura-se, por isso, nessa ficção, ou autoficção, e nessa crítica teórica: comentário, descrição, explicação, anedotas, histórias, vidas, pai e filho, pai e filha, mãe e filha, amantes, conclusões e dúvidas, a techné e o constructum, o facticius e o factum. É também por essas razões que esses textos, cujo próprio andamento é um dos seus objetos, por vezes não progridem muito bem, ou não funcionam sozinhos. Mancam, ao contrário, em vez de andar rapidamente. São, além de tudo, muito difíceis de fechar (DERRIDA, 1987 apud WILLS, 1995).

Logo, como suplemento, Leviatã, é articulado a Jogo duplo. Como a perna mecânica do pai, é um elemento estranho e ao mesmo tempo familiar. Faz parte do corpo do livro, na medida em que Sophie Calle costura suas páginas às páginas desse projeto, aos textos e fotos que surgem a partir do jogo duplo. À medida que sofre operações de inserção e corte, torna-se parte ainda mais orgânica, porém mantém sua diferença.

O jogo, como dissemos, é colaborativo. Necessita da participação da artista francesa, em primeiro momento, e depois de Paul Auster. No terceiro momento, o de Gotham Handbook (CALLE, 2007) , o movimento duplo se repete, e é mais uma vez na junção dos dois que surge a obra. Este é um trabalho que parte de outro, e com ele estabelece as regras, porém sem fechá-lo em uma só versão final. É como a tradução de um texto que, mesmo quando pronta, abre caminho para outras traduções, outras formas de leitura e de escritura. Jogo duplo pede, assim, ainda muitas leituras, trabalhos e escritas, e, como o pro(s)tético, sugere um andar cuidadoso, vacilante. 


\section{Referências}

ANTELO, R. Maria con Marcel: Duchamp en los trópicos. Buenos Aires: Siglo XXI Editores Argentina, 2006. 328 p.

AUSTER, P. Invisible. New York: Henry Hold and Company, 2009.

. Leviathan. New York: Penguin Books, 1993.

."The Invention of Solitude". In: Collected Prose. New York: Picador, 2010.

The New York Trilogy. London: Faber and Faber Limited, 2004.

BADIOU, A. Pequeno manual de inestética. Trad. de Marina Appenzeller. São Paulo: Estação Liberdade, 2002.

BARTHES, R. S/Z.. Trad. de Léa Novaes. Rio de Janeiro: Nova Fronteira, 1992.

BENJAMIN, W. "A obra de arte na era de sua reprodutibilidade técnica". In: A idéia do cinema. Trad. de José Lino Grünnewald. Rio de Janeiro, Civilização Brasileira, 1996.

BORGES, J. L. "Pierre Menard, autor do Quixote". In: Ficções. São Paulo: Editora Globo, 1998.

BUTLER, J. Relatar a si mesmo. Crítica da violência ética. Belo Horizonte: Autêntica, 2015.

CALLE, S. Double Game. England: Violette Editions, 2007.

. Histórias reais. Trad. de Hortencia Santos Lencastre. Rio de Janeiro: Agir Editora Ltda., 2009.

CAMUS, A. O estrangeiro. Trad. de Antônio Quadros. S./ ed., 1942. [Versão e-book]. Data da digitalização: 2000.

Derrida, J. Gramatologia. Trad. de Miriam Schnaiderman e Renato Janini Ribeiro. São Paulo: Perspectiva/Editora da Universidade de São Paulo, 1973.

. "Living On/Borderlines". In: Deconstruction and Criticism. Trad. de James Hulbert. New York: The Seabury Press, 1979. p. 75-176.

Dissemination. Trad. de Barbara Johnson. Chicago: The University of Chicago Press, 1981.

LIMA, J. D. de; EVARISTO, C. Conceição Evaristo: 'minha escrita é contaminada pela condição de mulher negra'. Entrevista ao Jornal Nexo. 26 maio 2017. Disponível em: $<$ https://www.nexojornal.com.br/entrevista/2017/05/26/Conceição-Evaristo-'minha-escrita-écontaminada-pela-condição-de-mulher-negra'>. Acesso em: 16 dez. 2019.

FOUCAULT, M. As palavras e as coisas: uma arqueologia das ciências humanas. Trad. de Salma Tannus Muchail. 8. ed. São Paulo: Martins Fontes, 2000.

. Isto não é um cachimbo. Trad. de Jorge Coli. Data de digitalização: 2004.

GARRAMUNO, F. Frutos estranhos: sobre a inespecificidade na estética contemporânea. Trad. de Carlos Nougué. Rio de Janeiro: Rocco, 2014. 


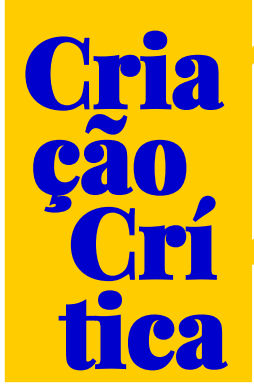

KORFMANN, M. "Transmedialidade ou iluminação recíproca entre as artes?". In: Travessia, v. 5, n. 2, 2011. Disponível em: <http://e-revista.unioeste.br/index.php/travessias/article/view/5749/4353>. Acesso em: 16 dez. 2019.

KRISTEVA, J. Estrangeiros para nós mesmos. Trad. de Maria Carlota Carvalho Gomes. Rio de Janeiro: Rocco, 1994.

LACAN, J. O seminário, livro 8: a transferência (1960-1961). Rio de Janeiro: Jorge Zahar Ed., 1992.

MALLARMÉ, S. Lance de Dados. Trad. De Álvaro Faleiros. São Paulo: Ateliê Editorial, 2014.

NANCY, J.-L. Corpus. Trad. de Tomás Maia. Lisboa: Veja Limitada, 2000.

PROUST, M. "No caminho de Swann - Combray". In: Em busca do tempo perdido. Trad. de Fernando Py. Rio de Janeiro: Ediouro, 2002.

POE, E. A. William Wilson. Trad. de Berenice Xavier. S. local: s. data. Disponível em: $<$ http://www.rodrigomedeiros.com.br/doubleyou/downloads/william-wilson-pt-br.pdf>. Acesso em: 09 de jan. de 2014.

ROUSSEAU, J.-J. The Confessions of J. J. Rousseau: with the Reveries of the Solitary Walker. v. 1. London: Printed for J. Bew, 1783. [Versão e-book].

WAUGH, P. Metafiction: the theory and practice of self-conscious fiction. Great Britain: Routledge, 1984.

WEISSTEIN, U. "Literature and the Visual Arts". In: BARRICELLI, J.; GIBALDI, J. (ed.) Interrelations of Literature. NY: Modern Language Association of America, 1982.

WILLS, D. "Paris, 1976". In: Prosthesis. Stanford: Stanford University Press, 1995, 350 p. 